\title{
Manajemen Pemeliharaan dan Pola Pemasaran Kelinci di Kecamatan Kabawetan Kabupaten Kepahiang
}

Jessi Desmiarti, Sutriyono*, Bieng Brata

Jurusan peternakan, Fakultas pertanian, Universitas Bengkulu.

Jalan. W.R Supratman Kandang Limun Bengkulu 38371A

*Korespondensi: sutri_yono_ok@yahoo.co.id

Artikel ini diterima (received): 18 Desember 2019; dinyatakan disetujui (accepted): 10 Februari 2020; terbit (published): 15 Mei 2020. Artikel ini dipublikasi secara daring pada https://ejournal.unib.ac.id/index.php/buletin_pt

\section{ABSTRAK}

Penelitian ini bertujuan untuk mengkaji manjemen pemeliharaan dan pola pemasaran ternak kelinci pada peternakan rakyat di Kecamatan Kabawetan Kabupaten Kepahiang. Variabel yang diamati; identitas responden, manajemen pemeliharaan ternak kelinci (pemilihan bibit, reproduksi, kandang dan fasilitasnya, pemberian pakan, dan pemberantasan penyakit), populasi ternak, dan pola pemasaran. Data yang diperoleh ditabulasi dan disajikan dalam bentuk tabel lalu di bahas secara deskriptif. Responden kelinci yang ada di Kecamatan Kabawetan sebanyak 17 orang. Hasil penelitian memnunjukkan bahwa peternak memilih bibit yang berasal dari indukan $(47,01 \%)$ dan anakan (52,95\%). Kelinci dikawinkan dengan cara alami dengan rasio jantan betina rata rata $1: 6$. Kandang adalah kandang baterai, beratap seng, berdinding bambu (82,35\%), dan lantai kandang, berbahan bambu $(94,12 \%)$. Pakan kelinci diberikan sebanyak dua kali dalam sehari. Jenis pakan yang diberikan; rumput lapang, wortel, daun singkong, kubis, daun sawi dan buncis. Sanitasi kandang dan pencegahan penyakit selalu dilakukan. Populasi ternak kelinci dalam 1 tahun terakhir sebanyak 4527 ekor; 304 indukan dan penjantan, 3220 dijual, 621 mati, 372 anakan, dan 10 ekor kelinci dipotong. Pola pemasaran ternak kelinci, semua peternak menjual hasil ternak mereka ke pedagang pengumpul. Kriteria penentuan harga dan waktu penjualan bibit ditentukan sendiri oleh peternak. Dapat disimpulkan bahwa sistem manajemen pemeliharaan ternak kelinci masih tradisional, peternak menjual langsung ke pedagang pengumpul. Kriteria penentuan harga dan waktu penjualan ternak ditentukan oleh peternak.

Kata kunci : Kelinci, manajemen pemeliharaan, pola pemasaran.

\section{PENDAHULUAN}

Keberhasilan peternak kelinci dipengaruhi oleh faktor antara lain faktor internal dan external. Manajemen pemeliharaan dan pemasaran yang harus diperhatiakan dalam pemeliharaan ternak kelinci. Manajemen pemeliharaan meliputi sistem perkandangan, sistem pemberian pakan, dan sistem penangulangan hama penyakit. Sedangakan menajemen pemasaran yang harus diperhatikan adalah pola pemasaran dan permintaan konsumen terhadap produk yang di pasarkan dari pasar ke pasar yang lainya. Manajemen pemeliharaan dan pola pemasaran yang baik akan memepengaruhi pendapatan peternak (Hustamin dan Dani, 2007; Raditya, 2006).
Kelinci lokal dan impor telah lama dipeliharah oleh masyarakat Bengkulu khususnya di Kabupaten Kepahiang yaitu Desa sekitar Kecamatan Kabawetan yang meliputi Desa, Tangsi Duren, Tugu Rejo Sumber Sari, Mekar Sari, Mekar Sari, dan Bandung Baru dengan pemeliharaan yang masi bersifat tradisional. Bila ditinjau dari segi lingkungan desa - desa tersebut cukup mempunyai potensi untuk perkembangan ternak kelinci. Sebagaimana diketahui, wilayah tersebut merupakan sentral sayur - mayur yang menjadi sumber pakan bagi kelinci. Ketinggian tempat 600 - 1.200 meter di atas permukaan laut, suhu rata - rata berkisar $20.5^{\circ} \mathrm{C}$ pada siang hari dengan rata - rata curah hujan 233.5 milimeter /bulan dengan ditribusi curah hujan merata 
sepanjang tahun (BPS, 2013). Namun demikian, lingkungan dan peserdiaan pakan yang cukup banyak belum tentu menghasilkan produktivitas yang baik jika tidak didukung oleh manajemen yang baik.

Manajemen pemasaran merupakan proses kegiatan aktivitas menyalurkan produk dari produsen ke konsumen. Pemasaran merupakan ujung tombak kegiatan ekonomi dalam agribisnis peternakan. Peternak atau pengusaha yang menghasilkan produk peternakan pasti menginginkan produknya sampai dan diterima oleh konsumen yang harus melalui beberapa kegiatan pemasaran (Rahadi dan Hartono, 2003).

Dalam kaitanya dengan rantai pemasaran ternak kelinci maka dalam penelitian ini akan mendeskripsikan pola pemasaran ternak yang dibangun melalui bagaimakah cara penjulan ternak, bagaimana kriteria penentuan harga dan waktu penjualan. Realitas terjadinya proses pemasaran ternak melalui jual beli antara peternak dan pedagang

\section{MATERI DAN METODE Waktu dan tempat}

Penelitian ini dilaksanakan pada tanggal 20 - 27 september 2015 yang berlokasi di Desa Tangsi Duren, Tugu Rejo, Sumber Sari, Mekar Sari, Suka Sari dan Bandung Baru. Kecamatan Kabawetan Kabupaten Kepahiang.

\section{Penentuan lokasi}

Penentuan lokasi ini ditetapkan secara purposive, yaitu desa desa yang terdapat peternak kelinci, dan dilakukan berdasarkan objek yang diteliti. Berdasarkan hasil penelitian lokasi yang terdapat ternak kelinci di Kecamatan Kabawetan Kabupaten Kepahiang yaitu : Desa Tangsi Duren, Tugu Rejo, Sumber Sari, Mekar Sari, Suka Sari dan Bandung Baru.

\section{Penentuan responden}

Responden ditentukan secara sengaja (purposive) yaitu seluruh peternak kelinci yang ada di Kabawetan Kabupaten Kepahiang. Berdasarkan survei data Perternak kelinci yang ada di Kabupaten Kabawetan Kabupaten Kepahiang adalah 17 orang peternak.

\section{Metode pengumpulan data}

Data yang dikumpulakan dalam penelitian ini adalah primer dan sekunder. Data primer diperoleh melalui pengamatan langsung ke lokasi penelitian dan mendatangi langsung peternak yang dipilih sebagai sampel dengan cara wawancara (dept interview) dan mengajukan daftar pertanyaan atau kuisioner yang telah dipersiapkan untuk mendapatkan informasi dari peternak, data primer terdiri dari : Indentitas Responden, bibit dan jenis ternak kelinci, manajemen pemeliharaan ternak kelinci (manajemen pemilihan bibit, reproduksi, kandang dan fasilitasnya, pemberian pakan dan pemberantasan penyakit), populasi ternak kelinci, pola pemasaran ternak kelinci. dan data sekunder dapat diperoleh dari data dan catatan yang sudah ada sebelumnya. Data tersebut bisa didapat dari instasi instasi dan lembagalembaga yang berkaitan dengan penelitian ini maupun literatur-literatur ataupun pustaka yang sudah ada.

Variabel yang diukur adalah manajemen pemeliharaan, jumlah kelinci dan pola pemasaran.

\section{Analisis data}

Data yang diperoleh ditabulasi dan disajikan dalam bentuk tabel lalu di bahas secara deskriptif.

\section{HASIL DAN PEMBAHASAN Manajemen pemeliharaan}

Pemelihan bibit ternak kelinci pada peternakan rakyat di Kecamatan Kabawetan meliputi : bibit ternak kelinci, asal bibit kelinci, jenis bibit, umur bibit, bobot bibit. Data - data tersebut dapat dilihat pada Tabel 1.

Berdasarkan Tabel 1 dapat di lihat bahwa peternak memilih bibit kelinci dari anakan sebanyak 9 orang dan yang memilih dari indukan sebanyak 8 orang. Peternak di Kabawetan menyatakan, memilih bibit ternak kelinci dari anakan maupun indukan memiliki kelebihan dan keurangan tersendiri. Bibit dari anakan relatif lebih murah harganya, namun pemeliharaan bibit kelinci anakan membutuhkan waktu yang panjang atau lama berkisar antara $7-8$ bulan untuk berproduksi atau menghasilkan anakan. Dengan demikian dalam kurung waktu yang lama, kelinci tersebut banyak terserang penyakit maupun ganguan predator lainya, sehingga ternak kelinci banyak yang mati sebelum berproduksi. Dilain pihak, bibit indukan memiliki waktu yang singkat untuk berproduksi, namun harga bibit kelinci yang berasal dari indukan relatif lebih mahal dibandingkan dengan harga bibit anakan. 
Tabel 1. Pemilihan bibit ternak kelinci pada peternakan rakyat di Kecamatan Kabawetan

\begin{tabular}{|c|c|c|c|}
\hline No & Keterangan & Jumlah (orang) & Presentase (\%) \\
\hline \multirow[t]{3}{*}{1} & Bibit ternak kelinci & & \\
\hline & Anakan & 9 & 52,95 \\
\hline & Indukan & 8 & 47,00 \\
\hline \multirow[t]{3}{*}{2} & Asal bibit & & \\
\hline & Asli indonesia (lokal) & 17 & 100 \\
\hline & Impor (keturunan impor) & 3 & 17,65 \\
\hline \multirow[t]{3}{*}{3} & Jenis bibit & & \\
\hline & Penghasil daging & 17 & 100 \\
\hline & Hewan hias & 3 & 17,65 \\
\hline \multirow[t]{3}{*}{4} & Umur bibit & & \\
\hline & $2-3$ bulan (anakan) & 9 & 52,95 \\
\hline & $8,5-10$ bulan (indukan) & 8 & 47,00 \\
\hline \multirow[t]{3}{*}{5} & Bobott bibit ternak & & \\
\hline & $250-500$ gram & 9 & 52,95 \\
\hline & $9-10 \mathrm{~kg}$ & 8 & 47,00 \\
\hline
\end{tabular}

Sumber : Data primer bulan september 2015

Pemilihan asal bibit ternak kelinci oleh peternak di kabupaten Kabawetan lebih banyak memilih bibit lokal atau asli Indonesia. Bibit kelinci yang berasal dari luar atau impor relatif memiliki harga yang lebih mahal dan susah didapatkan. Peternak yang memilih bibit asli indonesia atau lokal yaitu sebanyak 17 orang, sedangkan yang memilih bibit ternak yang berasal dari luar atau impor sebanyak 3 orang. Bibit kelinci asli Indonesia; kelinci Jawa (Lepus negricollis) dan kelinci impor, peranakan Anggora inggris dan Felmis giant. Hal ini sesuai dengan pernyataan Duta, (2008) pemerintah pernah menganjurkan agar kelinci dikembangkan sebagai ternak sumber daging untuk meningkatkan mutu gizi masyarakat. Namun, usaha tersebut gagal karena kelinci berkembang menjadi komoditas yang mahal, terutama harga bibitnya. Beberapa ras kelinci yang banyak dikembangkan secara komersial di Negara-negara Eropa, Amerika, dan juga Indonesia yaitu Anggora, Champagne d'Argent, Carolina, Checkered giant, Felmis giant, Dutch, English spot, dan Himalayan. Harga dari beberpa ras kelinci tersebut dapat dihargai mencapai jutaan.

Peternak yang memilih bibit kelinci penghasil daging sebanyak 17 orang dan bibit kelinci hias sebanyak 3 orang. Perbedaan tersebut sangat signifikan diantara bibit pedaging dan hias, dikarenakan bibit ternak kelinci yang berasal dari luar atau impor sulit didapatkan dan harga indukanya relatif mahal.
Selain itu, pemeliharaan kelinci jenis ini relatif lebih susah, mudah terserang penyakit, dan frekwensi perkelahiran lebih sedikit dibandingkan dengan ternak lokal, oleh sebab itu ternak kelinci impor ini memiliki harga yang lebih tinggi (Sari, 2007).

Pemilihan bibit anakan yang berumur 2 3 bulan dan ber bobot berkisar antara 250 300 gram sebanyak 9 orang peternak, sedangkan yang memilih ternak indukan yang berumur 8,5-10 bulan dengan bobot $9-10 \mathrm{~kg}$ yaitu sebanyak 8 orang peternak. Namun pernyataan ini tidak sesuai dengan pernyataan Raharjo (1993) bobot bibit anakan kelinci yang bagus memiliki berat 480 gram dengan umur 10 minggu. Sedangkan menurut Harsojo. et al (1988) bobot bibit badan keinci asli Indonnesia mencapai 2 kilogram pada umur 8 minggu dan memiliki laju pertumbuhan tinggi, sekitar 40 gram per ekor per hari.

Menurut Raharjo (2005), Kriteria bibit kelinci yang bagus yaitu : kepala yang seimbang dengan ukuran tubuhnya, telinga harus tegak, bersih, tebal, panjang, dan tampak seimbang, mata yang bulat bercahaya, bersih pandangan mata cerah dan jerni. Selanjutnya hidung dan mulut kering dan bersih, kaki kuat, kokoh, berkuku pendek, dan lurus tidak bengkok, badan bulat, berdada lebar, dan padat, bulu harusla bersih, licin, halus, mengkilat, dan ekor yang tegak, lurus ke atas menempel pada punggung.

Tabel 2. Data Sifat-sifat reproduksi ternak kelinci di Kecamatan Kabawetan Kabupaten Kepahiang 


\begin{tabular}{llll}
\hline No & Keterangan & Jumlah (Orang) & Presentase (\%) \\
\hline 1 & Perkawinan & 17 & 100 \\
& Alami & - & \\
$\quad$ Buatan & & 23,52 \\
$2 \quad$ Rasio jantan dan betina & 4 & 76,48 \\
& $\begin{array}{l}1: 4-1: 5 \\
\quad 1: 7-1: 10\end{array}$ & 13 & 100 \\
$3 \quad$ Perlakuan betina saat kawin & 17 & \\
& Dipisahkan & - & \\
& Tidak dipisahkan & &
\end{tabular}

Sumber : Data primer bulan september 2015

Tabel 3. Sistem perkandang ternak kelinci pada peternakan rakyat di Kecamatan Kabawetan Kabupaten Kepaghiang.

\begin{tabular}{|c|c|c|c|}
\hline No & Uraian & Jumlah (Orang) & Presentase (\%) \\
\hline \multirow[t]{8}{*}{1} & $\begin{array}{l}\text { Kontruksi Bahan kandang } \\
\text { a. Atap kandang }\end{array}$ & & \\
\hline & - Seng & 17 & 100 \\
\hline & b. Dinding kandang & & \\
\hline & - Bambu & 14 & 82,06 \\
\hline & - Papan & 3 & 17,07 \\
\hline & c. Lantai kandang & & \\
\hline & - Bambu & 16 & 94,12 \\
\hline & - Papan & 1 & 5,89 \\
\hline \multirow[t]{5}{*}{2} & Ukuran kandang baterai & & \\
\hline & $-75 \times 45 \mathrm{~cm}-80 \times 50 \mathrm{~cm}$ & 9 & 75,00 \\
\hline & $-95 \times 60 \mathrm{~cm}-100 \times 80 \mathrm{~cm}$ & 5 & 29,41 \\
\hline & Ukuran kandang koloni & & \\
\hline & $-3 \mathrm{M} \times 80 \mathrm{~cm}-4 \mathrm{M} \times 100 \mathrm{~cm}$ & 3 & 17,07 \\
\hline \multirow[t]{7}{*}{3} & Perlengkapan kandang & & \\
\hline & - Kandang induk bunting & 17 & 100 \\
\hline & - Kandang induk menyusui & 6 & 35,03 \\
\hline & - Kandang karantina & - & \\
\hline & - Kandang penjantan & 17 & 100 \\
\hline & - Tempat pakan & 6 & 35,20 \\
\hline & - Tempat air minum & 3 & 17,07 \\
\hline \multirow[t]{3}{*}{4} & Bentuk kandang & & \\
\hline & - Postal (kandang koloni) & 2 & 11,80 \\
\hline & - Baterai & 15 & 88,36 \\
\hline \multirow[t]{5}{*}{5} & Arah kandang & & \\
\hline & - Selatan & 4 & 23,53 \\
\hline & - Barat & 3 & 17,65 \\
\hline & - Utara & 3 & 17,65 \\
\hline & - Timur & 7 & 41,18 \\
\hline
\end{tabular}

Sumber : Data primer september 2015

\section{Reproduksi ternak kelinci}

Tabel 2 di bawah terlihat sifat sifat reproduksi ternak kelinci; cara perkawinan, rasio penjantan dan betina, sistem perkawinan. Berdasarkan Tabel 2 di atas dapat dilihat bahwa peternak kelinci yang ada di
Kecamatan Kabawetan 100\% mengawikan ternak kelinci mereka dengan cara alami. Peternak berpendapat bahwa ternak belum mempunyai potensi yang layak apabila harus dikawinkan dengan menggunakan kawin buatan karena frekwensi peternakan mereka yang masih dalam skala kecil. Selain itu, belum 
adanya tenaga ahli yang bisa mengawikan kelinci mereka dengan cara kawin buatan.

Rasio penjantan dan betina saat kawin, untuk rasio $1: 4-1: 5$ sebanyak 4 orang peternak sedangkan $1: 7-1: 10$ sebanyak 13 orang peternak. Penentuan rasio penjantan dan induk ini ditentukan sendiri oleh peternak yang ada di Kabawetan, sesuai dengan jumlah ternak penjantan dan induk yang dimiliki. Pejantan dapat dikawinkan setiap hari, tetapi sebaiknya dikawinkan 3 - 4 kali dalam seminggu. Satu ekor pejantan cukup untuk mengawini 10 - 15 ekor betina dewasa (Cheeke et al. 1987).

Pada dasarnya, sistem perkawinan ternak kelinci di kecamatan kabawetan sudah mengetahui, dimana ternaknya dipisahkan dengan ternak kelinci lainya. Hal ini ditunjukan bahwa peternak di Kabawetan 100 \% (17 peternak) sudah memisahkan ternak yang sedang kawin ke kandang yang khusus untuk kawin. Perlakuan sistem perkawinan ini harus dilakukan karena untuk meminimkan terjadinya perkawinan berulang atau repeat breeding.

\section{Manajemen perkandangan ternak kelinci.}

Bentuk dan kontruksi kandang kelinci pada peternakan kelinci di Kecamatan Kabawetan meliputi: kontruksi bahan kandang, ukuran kandang baterai, ukuran kandang koloni, perlengkapan kandang, bentuk kandang, arah kandang, terlihat pada pada Tabel 3.

Atap kandang adalah seng. Perlu memperhatikan ketahanan bahan, efisiensi pengunaaan dan harga bahan yang akan digunakan sebagain atap kandang tersebut (Herman 2002). Seng selain mahal juga tidak menyerap panas. Dengan demikian akan menyebabkan suhu ruanagan akan tinggi, akan berdampak pada fisiologis kelinci seperti stres akibat panas,sehingga dapat menurunkan produktivitas ternak kelinci. Pengunaan bahan atap yang tidak menyerap tidak memberikan kenyamanan bagi kelinci dalam kandang karena ternak kelinci sangat produktif jika dipelihara di kandang atau lingkungan yang sejuk dengan suhu $15{ }^{\circ} \mathrm{C}$ sampai $20{ }^{\circ} \mathrm{C}$ dan kelembaban $60 \%$ sampai $90 \%$ (Sarwono, 2001).

Pembuatan lantai kandang dapat menggunakan bahan - bahan seperti bahan dari kawat, bambu, papan, dan tanah (Basuki, 1985). Bahan lantai kandang yang digunakan oleh peternak di Kecamatan Kabawetan adalah bambu.

Kandang berupasistem kandang baterai dan koloni. Ukuran kandang baterai bervariasi ; $75 \mathrm{~cm} \times 44 \mathrm{~cm}-100 \mathrm{~cm} \times 80 \mathrm{~cm}$ sebanyak 9 orang dan ukuran kandang $95 \mathrm{~cm} \times 60 \mathrm{~cm}-$ $100 \mathrm{~cm} \times 80 \mathrm{~cm}$ sebanyak 5 orang, sisanya mengunakan kandang koloni dengan ukuran $3 \mathrm{~m} \times 80 \mathrm{~cm}-4 \mathrm{~m} \times 100 \mathrm{~cm}$ sebanyak 3 orang. Bervariasinya ukuran kandang di karenakan peternak tidak mengetahui ukuran kandang yang sesuai untuk setiap tingkatan umur kelinci, dan adanya keterbatasan modal untuk pembuatan kandang.

Menurut Subroto (2001), ukuran kandang sangat tergantung pada besar kecilnya kelinci dan jumlah kelinci yang dipelihara. Ukuran kandang berdasarkan tingkat umur adalah sebagai berikut :

a. Untuk kelinci yang masih kecil dengan ukuran kandang : panjang, lebar $=90 \times 60$ $\mathrm{cm}$.

b. Untuk kelinci ukuran sedang dengan ukuran kandang : panjang, lebar $=120 \times 60 \mathrm{~cm}$.

c. Untuk kelinci ukuran besar dengan ukuran kandang : panjang, lebar $=180 \times 60$

Bentuk kandang yang digunakan oleh peternak di Kabawetan adalah bentuk kandang baterai sebanyak 15 orang peternak dan sebagaian mengunakan sistem kandang postal sebanyak 2 orang peternak. Kandang postal sama halnya dengan kandang koloni, jadi semua ternak kelinci dikandangkan dengan kandang yang sama tampa mengunakan batas/skat seperti pada kandang baterai.

Pengunaan kandang baterai dan koloni memiliki keuntungan tersendiri, keuntungan pengunaan kadang baterai adalah mempermudah dalam melakukan sanitasi kandang, mencegah perkelahian dan kanibal, program pengembangbiakan dan pemulian dapat diatur lebih mudah, mencegah kematian anak kelinci karena terijak - injak oleh ternak yang lebih besar. Kelemahan penggunaan kandang ini adalah terletak pada biaya pembuatan kandang yang cukup tinggi. Namun demikian, kelemahan mengunakan kandang koloni adalah sering terjadi perkelahian antar kelinci, adanya kompetisi dalam segi perebutkan pakan, kurang terjaminya anak kelinci yang baru dilihirkan. Keuntungan pengunaan kandang koloni terletak pada biaya yang relatif lebih murah. 
Bangunan kandang dan peralatan perlu direncanakan untuk menghemat tenaga kerja dan biaya. Bagunan kandang dan peralatan yang diperlukan tergantung pada lokasi pembuatan kandang kelinci, besar peternakan dan besar modal dalam investasi (Herman, 2002).

Kandang kelinci bisa dibangun dalam berbagai bentuk sesuai dengan selera masing masing peternak atau tempat dimana kandang tersebut akan dibangun. Bentuk kandang kelinci bermacam - macam antara lain : 1 . Sistem baterai adalah suatu kandang yang terbagi menjadi beberapa ruang atau petak, 2 . Sistem postal kandnag siistim postal sangat cocok untuk memebesarkan anak kelinci karena beberapa kelinci dapat tinggal bersama dalam satu kandang, 3. Sisitem reng adalah sistem kandang yang memiliki halaman pengumbaran untuk bermain kelinci (Duta, 2008).

Arah kandang pada umumnya mengarah ke timur sebanyak 7 orang. Tujuan arah kandang mengarah ke timur agar sinar matahari pagi dapat masuk ke dalam kandang. Sinar matahari masuk langsung ke dalam kandang bertujuan untuk membunuh kuman atau bakteri yang ada di dalam kandang kelinci dan membunuh kuman yang ada ditubuh kelinci. Selain itu, sinar matahari pagi penghasil pro vitamin $D$ dan dapat juga menghangatkan tubuh kelinci (Anonim, 2007).

\section{Manajemen pemberian pakan kelinci}

Berdasarkan pada Tabel 4 terlihat, peternak yang ada di kecamatan Kabawetan memeberikan pakan ternak kelinci pada pagi dan sore hari. Pada pagi hari diberikan antara pukul $07.00-10.00$ WIB (Tabel 4). sedangkan sore hari diberikan berkisar pukul 16.00-18.00 WIB.

Hal ini berbeda, sebagai mana yang dikemukakan oleh Duta, (2001) pemberian pakan diberikan sebanyak 3 kali sehari, pada pukul 10.00 pemberian pakan pertama berupa bekatul ditambah garam dan air, pada pukul 13.00 pakan berupa rumput segar atau hijauan lain, dan pada pukul 18.00 diberikan pakan berupa rumput segar atau hijauan yang mengandung lebih banyak serat kasar.

Tabel 4. Tabel manajemen pakan ternak kelinci oleh peternak di peternakan rakyat Kecamatan Kabawetan Kabupaten Kepahiang.

\begin{tabular}{|c|c|c|c|}
\hline No & Uraian & $\begin{array}{l}\text { Peternak } \\
\text { (orang) }\end{array}$ & $\begin{array}{l}\text { Presentase } \\
\text { (\%) }\end{array}$ \\
\hline \multirow[t]{4}{*}{1} & Waktu pemberian pakan & & \\
\hline & Pagi & 17 & 100 \\
\hline & Siang & - & \\
\hline & Sore & 17 & 100 \\
\hline \multirow[t]{3}{*}{2} & Frekwensi pemberian pakan & & \\
\hline & 2 kali / hari & 17 & 100 \\
\hline & 3 kali / hari & - & \\
\hline \multirow[t]{3}{*}{3} & Jumlah pemberian pakan & & \\
\hline & $2-3 \mathrm{~kg}$ & 10 & 56,83 \\
\hline & $3,5-4 \mathrm{~kg}$ & 7 & 44,18 \\
\hline \multirow[t]{3}{*}{4} & Ketersediaan pakan & & \\
\hline & Ad libitum & - & \\
\hline & Dibatasi & 17 & 100 \\
\hline \multirow[t]{6}{*}{5} & Jenis pakan yang diberikan & & \\
\hline & Rumput lapang & 17 & 100 \\
\hline & Wortel & 17 & 100 \\
\hline & Kubis & 17 & 100 \\
\hline & Daun ubi jalar & 17 & 100 \\
\hline & Buncis & 9 & 52,95 \\
\hline
\end{tabular}

Sumber : Data primer bulan septermber 2015 
Jumlah pemberian pakan dalam satu kali pemberian sangat bervariasi, pemberian $1 \mathrm{~kg}$ sampai $4 \mathrm{~kg}$ per-satu kali pemberian. Peternak yang memberikan pakan $1-3 \mathrm{~kg}$ per-satu kali pemberian sebanyak 10 orang peternak dan 3,5 - $5 \mathrm{~kg}$ per-satu kali pemberian sebanyak 7 orang peternak. Pemberian pakan ternak diberikan 2 kali dalam satu hari sehingga rata - rata 2,5 kg per-harinya, dalam satu kandang ternak yang memiliki ternak i 4 - 6 ekor kelinci, indukan dan anakan.

Sarwono, (2001) menyatakan bahwa ternak kelinci dapat mengomsumsi hijauan sebanyak $1 \mathrm{~kg}$ sampai dengan 1,5 kg /ekor. Hijauan ini berasal dari limbah sayuran atau daun- dauanan. Dilain pihak, kelinci potong yang secara genetisnya berukuran besar dapat menghabiskan $2 \mathrm{~kg} / \mathrm{ekor} / \mathrm{hari}$. Jumlah pemberian $2 \mathrm{~kg} / \mathrm{ekor} / \mathrm{hari}$ sesuai dengan kebutuhan karena sekitar 90\% hijauan tersebut terdiri dari air.

Jenis bahan pakan untuk kelinci sebaiknya dipilih bahan pakan yang paling disukai oleh ternak kelinci. Bahan pakan tersebut mudah didapat, bisa tersedia secara kontinu, dan niai ekonomisnya relatif murah (Muslih et al., 2005).

Sarwono (2001), menyatakan bahwa pada peternakan kelinci yang dikekola secara insentif membutuhkan konsentrat sebanyak $60 \%$ dan sisanya diberikan pakan hijauan. Pemberian konsentrat berguna untuk menaikkan bobot badan kelinnci. Pada dasarnya kebutuhan nutrisi ternak kelinci yang ada di kabawetan belum dapat mencukupi kebutuhan nutrisinya. Hal ini dikarenakan, rata - rata jumlah pakan yang diberikan dalam sehari belum dapat mencukupi kebutuhsn gizi untuk satu ekor kelinci. Dengan demikian akan berdampak pada penurunan terhadap produktivitasnya.

\section{Manjemen pemberantasan penyakit}

Berdasarkan Tabel 5 dapat dilihat bahwa $100 \%$ peternak di Kabawetan selalu menjaga kebersihan kandang dan sanitasi kandang. Peternak di Kawawetan belum banyak mengunakan obat - obatan untuk ternak mereka. Namun demikian, sebagian peternak ada yang mengunakan obat - obatan berturutturut; calpanax, ipomex, wormectin, dan daun pisang sebanyak 2, 3, 1 dan 4 orang peternak.
Dosis pemberian obat diberikan sesuai dengan petunjuk yang sudah tertera pada label yang tertera pada obat. Waktu pencegeahan penyakit dilakukan setelah kelinci terserang penyakit.

Penyakit yang sering menyerang kelinci pada peternakan kelinci di Kabawetan; scabbies (sejenis penyekit kulit), bloat (masuk angin/kembung) dan pilek. Penyakit pilek terjadi karena perubahan cuaca yang drastis dimana kelinci sudah tidak dapat lagi mempertahankan suhu tubuhnya.

Pada umunya penyakit yang dialami peternak di peternakan kecamatn kabawetan adalah kembung. Pada umumnya peternak tidak tahu cara menangulangi penyakit kembung, sehingga bila kelinci terserang maka langsung dilakukan pemotongan untuk yang sudah dewasa atau siap untuk dipotong. Dilain pihak untuk kelinci yang anakaan biasanya diberikan daun pisang sebagai obat untuk penyakit kembung. Untuk ganguan kulit sebagian peternak biasanya mengunakan obat anti biotik kulit seperti kalpanax.

\section{Populasi Ternak Kelinci}

Jumlah populasi ternak kelinci dalam satu tahun terakhir; 4527 ekor, penjantan dan indukan sebanyak 304 ekor. Penjualan ternak sebanyak 3220 ekor, jantan dan betina. Berdasarkan tingkat kematian, cukup tinggi, 621 ekor satu tahun terkhir. Kematian kelinci banyak terjadi pada anakan, akibat terkena penyakit kembung. Pemotangan kelinci jarang dilakukan oleh peternak dimana dalam satu tahun terakhir jumlah kelinci yang dipotong hanya10 ekor kelinci.

Populasi ternak kelinci yang paling banyak terdapat pada peternak 13 , sebanyak 441 ekor ternak kelinci pertahunya. Namun demikian, populasi yang paling sedikit teradapat pada peternak 8 dengan jumlah 118 ekor dalam satu tahun terakhir dengan jumlah indukan dan penjantan sebanyak 8 ekor dan sisanya anakan. Angka penjualan yang paling tinggi terjadi pada peternak 13. Penjualan tertingi pada peternak 13 karena peternak tersebut memiliki indukan dan penjantan paling banyak bila dibandingkan dengan penternak lainya. 
Tabel 5. Pecegahan dan pengobatan penyakit pada peternakan kelinci di Kecamatan Kabawetan Kabupaten Kepahiang .

\begin{tabular}{|c|c|c|c|}
\hline No & Keterangan & $\begin{array}{l}\text { Jumlah } \\
\text { (orang) }\end{array}$ & $\begin{array}{l}\text { Presentase } \\
\text { (\%) }\end{array}$ \\
\hline \multirow[t]{3}{*}{1} & Selalu menjaga kebersihan kandang & & \\
\hline & YA & 17 & 100 \\
\hline & TIDAK & - & \\
\hline \multirow[t]{2}{*}{2} & Pencegahan penyakit kelinci & & \\
\hline & Sanitasi kandang & 17 & 100 \\
\hline \multirow[t]{5}{*}{3} & Obat yang digunakan & & \\
\hline & Calpanax & 2 & 11,08 \\
\hline & Ipomek & 3 & 17,08 \\
\hline & Wormectin & 1 & 05,09 \\
\hline & Daun pisang & 4 & 23,6 \\
\hline \multirow[t]{4}{*}{4} & Waktu pencegahan penyakit & & \\
\hline & Sebelum terserang & - & - \\
\hline & Sedang terserang & 10 & 56,83 \\
\hline & Sesudah terserang & - & - \\
\hline
\end{tabular}

Sumber : Data primer september 2015

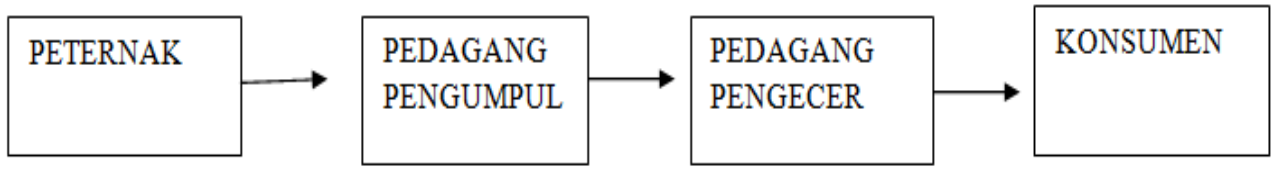

Gambar 1. Saluran pemasaran ternak kelinci di Kabawetan

\section{Pola pemasaran ternak kelinci}

Seratus persen peternak di Kabawetan menjual hasil peternakan kelincinya kepada pedagang pengumpul. Pedagang pengumpul menjualanya kembali ke pedagang pengecer dan pedagang pengecerlah yang langsung menjual ke konsumen. Ganbar 1 di bawah terlihat cara pemasaran ternak kelinci di Kecamatan Kebawetan Kabupaten Kepahyang. Terlihat pemasaran ternak kelinci, dimulai dari peternak kelinci sebagai produsen sampai ke konsumen. Secara umum pemasaran ternak kelinci disajikan dalam gambar 1 di atas. Hasil produksi ternak kelinci peternak disalurkan atau dijual langsung ke pedagang pengumpul Pedagang pengumpul selanjutnya disalurkan atau dijual kepedagang pengecer. Pedadang pengencer yang menjual langsung kepada konsumen. Adapun alasan peternak menjual ternak kepada pedagang pengumpul dimana pedagang pengumpul langsung mengambil seluruh ternak yang mau dijual. Cara pembayaran, $70 \%$ dimuka dan sisanya $30 \%$, dibayar setelah ternak kelinci yang ada di pedagang pengumpul semuanya terjual. Pembayaran sisa $30 \%$ dilakukan agar supaya pedagang pengumpul masih ada keterkaitan dengan peternak.

Berdasarkan hasil penelitian terlihat pola pemasaran ternak kelinci yang ada di Kecamatan Kabawetan. Cara penjualan ternak kelinci, kriteria penentuan harga, dan waktu penjualan ternak kelinci. Kriteria penenentuan harga kelinci yang di jual pada peternakan kelinci yang ada di Kecamatan Kabawetan 100\%, 17 peternak ditentukan oleh peternak. Penentuan harga ini ditentukan sendiri oleh peternak karena di daerah Kabawetan Kabupaten Kepahiang belum ada standarisasi harga untuk penjualan ternak kelinci tersebut.

Waktu penjualan ternak dalam penelitian ini; bibit, siap produksi dan indukan kelinci. Pada peternakan kelinci yang ada di Kecamatan Kabawetan 100\%, 17 peternak menjual hasil produksi peternakan kelinci mereka pada waktu ternak kelinci masih berumur kurang lebih 8 minggu atau bibit kelinci. Hal ini dikarena apabilah ternak kelinci dijual pada waktu sudah siap potong dan indukan membutuhkan waktu yang lebih lama dalam pemeliharaanya. Dengan demikian, bisa menimbulkan biaya dan tenaga yang lebih untuk pemeliharaanya sedangkan jumlah hasil 
jual indukan dan siap potong tidak jauh berbeda.

\section{KESIMPULAN}

Sitem manajemen pemeliharaan ternak kelinci di Kecamatan Kabawetan masih masih tradisional. Sistem pola pemasaran yang ada di peternakan rakyat Kecamatan Kabawetan yaitu semua peternak menjual hasil produksi ternak mereka kepedagang pengumpul. Kriteria penentuan harga dan waktu penjualan ternak ditentukan oleh peternak

\section{DATAR PUSTAKA}

Anonim, 2007. Permintaan Melonjak, Ternak Kelinci Prospektif. Yogyakarta. Kompas html. Diakes 10 oktober 2015.

Basuki, P. 1985. Studi tipe kandang kereman, panggung, individual dan kualitas pakan tehadap performans produksi kelinci. Laporan Penelitian. Fakultas Peternakan. Universitas Gajah Mada. Yogyakarta.

Cheeke, P.R., N.M. Patton, S.D. Lukefahr dan J.I. McNitt. 1987. Rabbit Production. 6th Edition. The Interstate Printers and Publishers, Inc., Danville. Illinois.

Duta, N.W. 2008. Analisis Kelayakan Usaha Peternakan Kelinci Asep't Rabbit Project, Lembang Kabupaten Bandung, Jawa Barat. Program Studi Manajemen Agribisnis. Fakultas Pertanian. Insitut Pertanian Bogor.

Harsojo, D. dan C.K.S. Lestari. 1998. Pengaruh bobot badan kelinci persilangan jantan akibat perbedaan waktu pemberian pakan. Pros. Seminar Nasional Peternakan dan Forum Peternak Unggas dan Aneka Ternak II. Balai Penelitian Ternak, Pusat Penelitian dan Pengembangan Peternakan, Badan Litbang Pertanian, Bogor.

Herman, R. 2002. Pengenalan Kandang dan Peralatan Ternak Kelinci. Departemen Pendidikan Nasional, Jakarta.

Hustamin, R. dan Dani. 2007. Panduan Memelihara Kelinci Hias. Cetakan ketiga. Agro Media Pustaka. Jakarta.
Muslih, D., I.W. Pasek, Rossuartini, dan B. Brahmantiyo. 2005. Tatalaksana pemberian pakan untuk menunjang agribisnis kelinci. Lokakarya Nasional Potensi dan Peluan Pengembangan Usaha Kelinci. Balai Penelitian Ternak, Bogor. Pond, W. G., D. C.

Raditya, 2006. Analisis Hubungan Struktur Kepemilikan dengan Kinerja Keuangan Perusahaan Perbankan Persero dan Perusahaan Swasta Nasional. Jurnal Fakultas Ekonomi Universitas Islam Indonesia Yogyakarta.

Rahardi, F., dan Hartono, R. 2003. Agribisnis Peternakan. Penebar Swadaya, Jakarta.

Raharjo, Y.C. Wijana Dan T. Sartika. 1993. Pengaruh jarak kawin setelah beranak terhadap performans reproduksi kelinci Rex. Ilmu Petern. 6: 27-31.

Raharjo, Y. C. 2010. Prospek, Peluang, dan Tantangan Agribisnis Ternak Kelinci. Prosiding. Disajikan pada Lokakarya Nasional Potensi dan Peluang Pengembangan Usaha Kelinci. Balai Penelitian Ternak. Bogor.

Raharjo, Y.C. 2005. Prospek, peluang, dan tantangan agribisnis ternak kelinci. Lokakarya Nasional Potensi dan Pengembangan Usaha Kelinci. Balai Penelitian Ternak, Bogor.

Triastono, H. 2013. Pengaruh faktor sosial ekonomi terhadap pendapatan dan efisiensi usaha peternak kelinci di kabupaten banyumas. Fakultas Peternakan Universitas Jenderal Soedirman, Purwokerto.

Sarwono, B. 2001. Kelinci Potong dan Hias. Agro Media Pustaka. Jakarta.

Sari, K.M. 2007. Pola pembibitan kelinci rakyat di paguyuban peternak kelinci di Kabupaten Magelang. Skripsi. Institut Pertanian Bogor, Bogor.

Subroto, S. 2001. Beternak Kelinci. Aneka IImu, Semarang. 